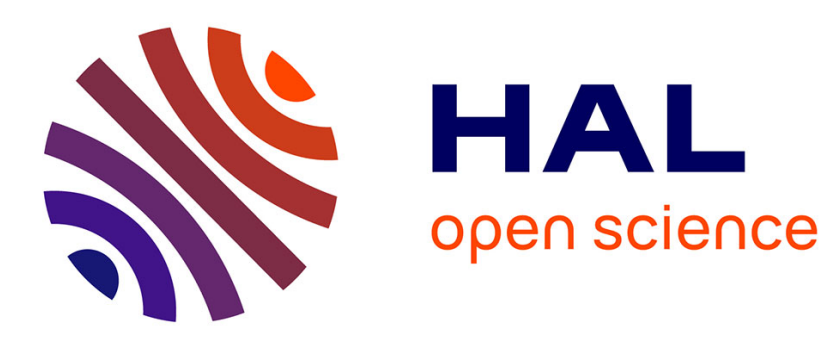

\title{
EXAFS Study of Zn and ZnEDTA Sorption at the Goethite $(\alpha-\mathrm{FeOOH}) /$ Water Interface
}

\author{
M. Schlegel, A. Manceau, L. Charlet
}

\section{To cite this version:}

M. Schlegel, A. Manceau, L. Charlet. EXAFS Study of Zn and ZnEDTA Sorption at the Goethite $(\alpha-\mathrm{FeOOH}) /$ Water Interface. Journal de Physique IV Proceedings, 1997, 7 (C2), pp.C2-823-C2-824. 10.1051/jp4:1997248 . jpa-00255327

\section{HAL Id: jpa-00255327 https://hal.science/jpa-00255327}

Submitted on 1 Jan 1997

HAL is a multi-disciplinary open access archive for the deposit and dissemination of scientific research documents, whether they are published or not. The documents may come from teaching and research institutions in France or abroad, or from public or private research centers.
L'archive ouverte pluridisciplinaire HAL, est destinée au dépôt et à la diffusion de documents scientifiques de niveau recherche, publiés ou non, émanant des établissements d'enseignement et de recherche français ou étrangers, des laboratoires publics ou privés. 


\title{
EXAFS Study of Zn and ZnEDTA Sorption at the Goethite $(\alpha-\mathrm{FeOOH}) /$ Water Interface
}

\author{
M.L. Schlegel, A. Manceau and L. Charlet \\ Environmental Geochemistry Group, LGIT-IRIGM, UJF, BP. 53, 38041 Grenoble cedex 9, France
}

\begin{abstract}
EXAFS spectroscopy has been used to compare the sorption mechanism of $\mathrm{Zn}$ and $\mathrm{ZnEDTA}$ on goethite $(\alpha-\mathrm{FeOOH})$. In the absence of EDTA, $\mathrm{Zn}$ is found to form an inner-sphere surface complex. Based on $\mathrm{Zn}-\mathrm{O}$ and $\mathrm{Zn}-\mathrm{Fe}$ distances, $\mathrm{Zn}$ is inferred to be located in a distorted oxygen octahedron which shares edges and/or corners with surface Fe octahedra. EXAFS spectra of ZnEDTA in solution and sorbed on goethite are similar, indicating that the ZnEDTA complex does not dissociate following its sorption. The absence of an Fe shell within the first $4 \AA$ precludes the existence of $\mathrm{Zn}$-O-Fe bonds and allows us to reject a ligand exchange sorption mechanism involving the formation of $\mathrm{Zn}-\mathrm{O}-\mathrm{Fe}$ linkages.
\end{abstract}

\section{INTRODUCTION}

The fate of trace metals in natural aquatic systems is influenced by adsorption processes at the oxide-water interface. The nature of these reactions and the amount of sorbed species can be modified by the presence of natural or anthropogenic organic ligands. For instance, complexation of $\mathrm{Zn}$ by the synthetic chelating agent EDTA $\left(\mathrm{C}_{10} \mathrm{H}_{12} \mathrm{O}_{8} \mathrm{~N}_{2}\right)$ has been shown to enhance its mobility in aquifers [1]. The sorption of Me-EDTA complexes on different oxide surfaces has been studied by means of batch chemical experiments ([2,3] and ref. therein) : MeEDTA exhibit a ligand-like, ionic strength-dependent sorption behavior. Contrasting molecular mechanisms (i.e. outer-sphere complexation [2] versus inner-sphere ligand exchange [3]), have been proposed to account for similar chemical results. To gain further insight on the influence of EDTA in the sorption mechanism of $\mathrm{Zn}, \mathrm{Zn}$-EXAFS experiments were performed on $\mathrm{Zn}$ - and $\mathrm{ZnEDTA}$-sorbed goethite.

\section{EXPERIMENTAL}

All chemicals were ACS reagent grade. Adsorption experiments were conducted at $25.0 \pm 0.1^{\circ} \mathrm{C}$ in a thermostated glass vessel, at a constant background electrolyte concentration $\left(\mathrm{NaNO}_{3} 0.1 \mathrm{~mol}^{-1}\right.$ ). Humidified argon was bubbled through a 15 g. $1^{-1}$ stirred suspension of goethite $\left(49 \pm 5 \mathrm{~m}^{2} \cdot \mathrm{g}^{-1}\right)$ to maintain a $\mathrm{CO}_{2}$-free atmosphere. The proton site concentration in the suspension was $2.10^{-3}$ mol. ${ }^{-1}$. $\mathrm{Zn}$ sorption at $10 \%$ proton site coverage was realized by adding an acid aliquot of $\mathrm{Zn}\left(\mathrm{NO}_{3}\right)_{2}$ ( Tot $\mathrm{Zn}=2.10^{-4} \mathrm{M}$ ) to the suspension at $\mathrm{pH} \mathrm{4}$, and then titrating the suspension with $\mathrm{NaOH} 0.1 \mathrm{~mol} . \mathrm{I}^{-1}$ up to $\mathrm{pH} 7$. The suspension was equilibrated at $\mathrm{pH} 7$ for $24 \mathrm{~h}$. ZnEDTA sorption on goethite at $30 \%$ site coverage was realized by titrating a ZnEDTA rich suspension (TotZnEDTA $=1.8 .10^{-3} \mathrm{M}$ ) from $\mathrm{pH} 9$ to $\mathrm{pH} 4.5$, and then equilibrating the suspension at $\mathrm{pH} 4.5$ for $30 \mathrm{~min}$. Both samples were filtered (Sartorius $0.1 \mu \mathrm{m}$ ), washed with $\mathrm{pH}$-adjusted $\mathrm{NaNO}_{3} 0.1$ mol. $\mathrm{I}^{-1}$, air-dried and loaded as powders in sample holders. Washingmay only remove the most weakly sorbed ions

Zn K-EXAFS spectra were recorded in fluorescence mode at the SRS synchrotron facility in Daresbury UK, on the EXAFS 9.2 station. Interatomic distances were determined on Fourier-filtered spectra by using phases and amplitudes functions either extracted from model compounds ( $\mathrm{ZnO}$ for the $\mathrm{Zn}-\mathrm{O}$ atomic pair, $\gamma-\mathrm{FeOOH}\left(\mathrm{FFe}_{\mathrm{Fe}}\right)$ ) or calculated [4].

\section{RESULTS AND DISCUSSION}

\subsection{Zn sorbed goethite}

$\chi(\mathrm{k})$ spectra and RDFs of $\mathrm{Zn}$ sorbed goethite (\#a), ZnEDTA in solution (\#b) and ZnEDTA sorbed goethite (\#c) are displayed in Fig. 1 and 2. The RDF for \#a presents one main peak at $1.7 \AA$, which corresponds to the contribution of the $\mathrm{Zn}-\mathrm{O}$ coordination shell, and a broad double-peak extending from 2.5-3.0 $\AA$. Two $\mathrm{Zn}-\mathrm{O}$ distances were determined from the fitting of the Fourier-filtered $\mathrm{Zn}-\mathrm{O}$ contribution: $\mathrm{d}_{\mathrm{Zn}-\mathrm{O} 1}=2.01 \AA(\mathrm{N}=3.5)$ and $\mathrm{d} \mathrm{Zn}-\mathrm{O2}=2.19 \AA(\mathrm{N}=3.2)$. $<\mathrm{d}_{\mathrm{Zn}-\mathrm{O}}>$ is equal to $2.10 \AA$, which is typical of six-coordinated $\mathrm{Zn}(2.12 \AA,[5]) . \mathrm{d}_{\mathrm{Zn}-\mathrm{Ol}}$ can hardly be attributed to four-fold $\mathrm{Zn}$, as $\left.\left.\left\langle\mathrm{d}_{1}{ }^{1 \mathrm{v}} \mathrm{Zn}-\mathrm{O}\right)\right\rangle=1.97 \AA\right)$, but is found in distorted $\mathrm{Zn}$ octahedra [6]. Thus, $\mathrm{Zn}$ is inferred to be located in a distorted octahedron.

The broad peak at 2.5-3.0 $\AA$ on the RDF is absent for solvated $\mathrm{Zn}$, and points to the presence of $\mathrm{Zn}$-metal interactions. Since the suspension contained only $\mathrm{Zn}$ and $\mathrm{Fe}$, only these atoms can contribute to these RDF peaks. A comparison of the EXAFS spectrum for $\#$ a with the spectrum of amorphous $\mathrm{Zn}(\mathrm{OH})_{2}$ (Fig. 1) indicates that the local structures of $\mathrm{Zn}(\mathrm{OH})_{2}$ and $\mathrm{Zn}$ sorbed goethite are different. This observation allows us to reject the precipitation of $\mathrm{Zn}$ hydroxide. Therefore one can 
assume that these metal shell peaks come from contributions of surface Fe atoms, i.e. that $\mathrm{Zn}$ forms an inner-sphere surface complex. Zn-Fe contributions were modeled by two Fe shells at $3.00 \AA(\mathrm{N}=0.9)$ and $3.20 \AA(\mathrm{N}=1.2)$. These distances are in good agreement with those determined for Cd-sorbed goethite $\left(\mathrm{d}_{\mathrm{Cd}-\mathrm{Fe}}=3.26\right.$ and $3.48 \AA$, [7]), taking into account the difference of ionic radii between 6 -fold $\mathrm{Zn}$ and $\mathrm{Cd}\left(\mathrm{r}_{\mathrm{Zn}}=0.74 \AA\right.$ and $\mathrm{r}_{\mathrm{Cd}}=0.95 \AA$; [5]). As for cadmium, the short $\mathrm{Zn}-\mathrm{Fe}$ distance is attributed to an edge linkage between $\mathrm{Zn}$ and surface $\mathrm{Fe}$ octahedra, and the longer distance to a corner linkage.

In conclusion, $\mathrm{Zn}$ octahedra are found to share edges and corners with surface Fe octahedra. By analogy with Cd [7], these two types of linkage are believed to correspond to different surface sites.

\subsection{ZnEDTA sorbed goethite}

The strong organometallic complex formed by $\mathrm{Zn}$ and EDTA in solution may adopt several conformations similar to those determined in crystals. For example, in $\mathrm{Mg}\left[\left(\mathrm{H}_{2} \mathrm{O}\right)_{4} \cdot \mathrm{ZnEDTA}\right] \cdot 2 \mathrm{H}_{2} \mathrm{O}$ [8], $\mathrm{Zn}$ is coordinated to 4 acetyl and 2 amide groups of the EDTA molecule. In solution, this hexadentate conformation is in equilibrium with a pentadentate one, the coordination sphere of zinc being completed by a water oxygen. In both conformations, $\mathrm{Zn}$ is coordinated to $\mathrm{N}$ and $\mathrm{O}$ atoms, and has 10 next-nearest $\mathrm{C}$ neighbors. The RDF of ZnEDTA in solution (\#b) displays 3 major peaks centered at $1.7 \AA, 2.5 \AA$ and $3.5 \AA$. The first two peaks correspond to $(\mathrm{N}, \mathrm{O})$ and $\mathrm{C}$ contributions, respectively. They were modeled by two (N, $\mathrm{O}$ ) subshelis at 2.07 $\AA(\mathrm{N}=3.4)$ and $2.20 \AA(\mathrm{N}=2.1)(\langle\mathrm{d} \mathrm{Zn}(\mathrm{O}, \mathrm{N})\rangle=2.12 \AA)$, and two $\mathrm{C}$ subshells at $2.82 \AA \mathrm{N}=3.8)$ and $2.95 \AA(\mathrm{N}=7.1)\left(\left\langle\mathrm{d} Z \mathrm{n}-\mathrm{C}^{>}\right.\right.$ $=2.90 \AA)$. These mean distances are close to those found in solid structures $\left(<\mathrm{d}_{\mathrm{Zn}-}(\mathrm{O}, \mathrm{N})\right\rangle=2.11 \AA$ and $\left\langle\mathrm{d}_{\mathrm{Zn}-\mathrm{C}}\right\rangle=2.89 \AA$; [8]). Due to the absence of heavy metal near $\mathrm{Zn}$, the third RDF peak cannot be assigned to a cationic shell. $A b$ initio calculations performed on ZnEDTA clusters derived from the $\mathrm{Mg}\left[\left(\mathrm{H}_{2} \mathrm{O}\right)_{4} \cdot \mathrm{ZnEDTA}\right] \cdot 2 \mathrm{H}_{2} \mathrm{O}$ crystalline structure [8], using FEFF6 [9] showed that this third RDF peak predominantly corresponds to multiscattering contributions.

Fig. 2 shows that ZnEDTA in solution $(\# b)$ and sorbed on goethite $(\# c)$ have very similar EXAFS spectra and RDFs, and that they are markedly different from $\mathrm{Zn}$-sorbed goethite. This result indicates that the structure of ZnEDTA was preserved during sorption. A quantitative spectral analysis of \#c yielded interatomic distances which were, to the precision of the method, identical to those obtained for \#b. The third peak for sample \#c is shifted toward shorter $\AA$ values. This may result from slight structural distortions. No Fe-Zn pairing could be identified below $4 \AA$. Solely external oxygens of the EDTA molecule, that are not bound to the $\mathrm{Zn}$ atom, may possibly interact with surface Fe octahedra, but in this case, the Fe atoms would be at much higher distance than $4 \AA$ from $Z n$ and would not be detected by EXAFS spectroscopy.

In conclusion, EXAFS spectroscopy indicates that the conformation of the ZnEDTA complex is preserved during sorption on goethite and precludes a ligand exchange sorption mechanism involving the formation of $\mathrm{Zn}-\mathrm{O}$-Fe linkages. This conclusion may be generalized to several other MeEDTA ( $\mathrm{Me}=\mathrm{Ca}, \mathrm{Zn}, \mathrm{Cu}, \mathrm{Co}(\mathrm{II}), \mathrm{Pb}$ ) complexes, inasmuch as these complexes show similar macroscopic sorption behaviors on goethite [3].

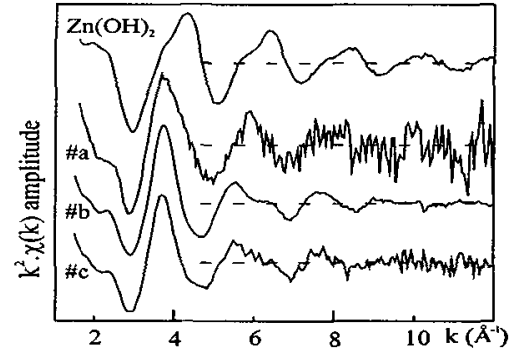

Fig. 1: $\mathrm{k}^{2}, \chi(\mathrm{k})$ spectra for $\mathrm{Zn}(\mathrm{OH})_{2}, \mathrm{Zn}$ sorbed goethite (\#a), ZnEDTA in solution (\#b) and ZnEDTA sorbed goethite (\#c)

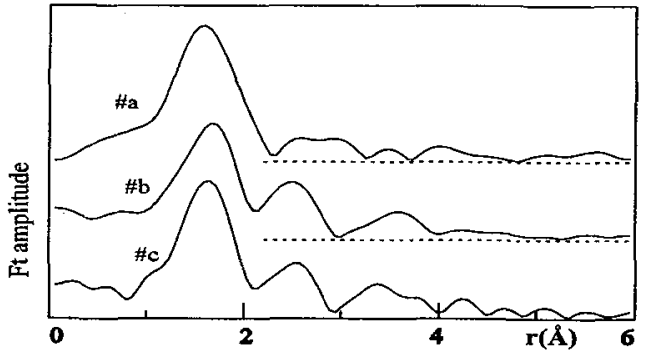

Fig. 2: RDF for $\mathrm{Zn}$ sorbed goethite (\#a), ZnEDTA in solution (\#b) and ZnEDTA sorbed goethite $(\# c)$

\section{Acknowledgement}

We thank the Daresbury staff for providing the X-Ray beam and for their technical assistance.

\section{References}

[1] Kent D.B., Davis J.A., Anderson L.D. and Rea B.A., "Ligand enhanced transport of strongly adsorbing ions in the groundwater environment", Water-Rock interactions (Karaka Y.K and Maes A.S., Eds, Balkema, Rotterdam, 1992)

[2] Bowers A.R. and Huang C.P., J. Coll. Interf. Sci, 110 (1986) 575-590.

[3] Nowack B. and Sigg L., J. Coll. Interf. Sci, 177 (1996) 106-12].

[4] McKale A.G., Veal B.V., Paulikas A.P., Chan S.K. and Knapp J.S., J. Am. Chem. Soc., 110 (1988) 3763-3768.

[5] Shannon R.D., Acta Cryst., A32 (1975) 751.767.

[6] Wadsley A.D., Acta Cryst., 8 (1955) 165-172

[7] Spadini L., Manceau A., Schindler P.W., Charlet L:, J. Coll. Interf. Sci, 167 (1994) 73-86.

[8] Solans X., Font-Alba M., Oliva J. and Herrera J., Acta Cryst., C39 (1983) 1435-1438.

[9] Rehr J.J., Albers R.C. and Zabinsky S.I., Phys. Rew. Lett., 69 (1992) 3397-3400. 